\title{
El concepto de cultura como clave para el análisis de la relación entre las subjetividades e instituciones en G. Deleuze.
}

Gulino Pablo Martín. UNNE. Facultad de Humanidades.

\section{Resumen.}

El presente trabajo pretende señalar al concepto de cultura expresado en la obra Nietzsche y la filosofía de G. Deleuze, como una clave para comprender la producción de subjetividades e instituciones así como la relación entre ambas. De este modo, pretendemos señalar a la cultura como el elemento que nos muestra la compleja trama de fenómenos en la que se ve envuelta la producción de sujetos e instituciones. Así también, y en relación con esta complejidad, se inscribe una manera no causal de comprender la relación entre las instituciones y los sujetos. De esta forma, entendemos que la cultura puede ser entendida como el concepto que nos permite observar la complejidad que esconde la producción de sujetos e instituciones así como su relación no lineal entre estas.

\section{Abstract}

The present work aims to point to the concept of culture expressed in the work Nietzsche and the philosophy of G. Deleuze, as a key to understand the production of subjectivities and institutions as well as the relationship between both. In this way, we intend to point to culture as the element that shows us the complex web of phenomena in which the production of subjects and institutions is involved. Thus, and in relation to this complexity, a non-causal way of understanding the relationship between institutions and subjects is inscribed. In this way, we understand that culture can be understood as the concept that allows us to observe the complexity that hides the production of subjects and institutions as well as their non-linear relationship between them.

\section{Introducción:}

En el presente trabajo intentaremos desarrollar los conceptos de cultura, sujetos e instituciones desde la perspectiva dada por G. Deleuze en su libro Nietzsche y la filosofía. Asimismo, en un comienzo abordaremos su noción de cultura en general para luego observar sus características específicas y los elementos que se vinculan a esta. Luego, en relación a las subjetividades, desarrollaremos el concepto deleuziano de fuerzas para comenzar a dar a conocer los tipos de sujetos que se vinculan con la 
cultura. De este modo, nos adentraremos en la noción de subjetividades en Deleuze siempre intentando ver sus vínculos con la cultura. Asimismo, también se tratará tangencialmente la noción de superhombre y su relación con las subjetividades. Posteriormente, desplegaremos el tratamiento que hace Deleuze entorno a las instituciones y su vínculo con la cultura. Finalmente, se intentará observar la relación entre las instituciones y las subjetividades en torno a la cultura.

\section{Deleuze y el concepto de cultura.}

El pensador francés reconoce a la cultura como un concepto que engloba un conjunto de elementos. Así, por ejemplo, hace referencia a este carácter de la cultura en un pasaje de su libro: "Este problema es tan complejo que, según Nietzsche, pone en juego el conjunto de fenómenos que se llama cultura." ${ }^{107}$

Asimismo, la noción de cultura cobra gran importancia en el armado del texto deleuziano. Si partimos de este concepto, podemos ir realizando un nuevo recorrido a través de los sus análisis. Así, Deleuze hablará repetidas veces a lo largo de su obra a cerca de la cultura e inclusive le dedicará tres títulos dentro de la cuarta sección de su libro. En principio nos centraremos en estos puntos destacados por el pensador francés, para luego señalar otros elementos vinculados a la cultura. Sin embargo, dejaremos afuera de este primer análisis lo que refiere al punto de vista posthistórico, puesto que se encontraría más emparentado al problema de las subjetividades que abordaremos más adelante. Asimismo, en los otros dos nos centraremos casi exclusivamente al concepto de cultura, si bien el autor continuamente traza relaciones con las instituciones y los tipos de sujetos.

Pasando ahora a una definición de cultura, en términos generales debemos decir que la misma debe ser comprendida como adiestramiento y selección. ${ }^{108}$ Más adelante veremos cómo estos dos elementos se vinculan a los dos tipos de culturas que vamos a diferenciar y qué nuevas características aparecen. Luego, sobre el final de esta parte haremos una reconstrucción del concepto agregando los demás elementos.

\footnotetext{
${ }^{107}$ DELEUZE, Gilles: Nietzsche y la filosofía, Anagrama, Barcelona, 2002., p. 187

108 "la cultura es adiestramiento y selección." Ibíd., p. 187
} 


\subsection{La cultura desde la prehistoria.}

El primer apartado que Deleuze le confiere a la cultura tratará principalmente la noción de cultura desde este punto de vista ${ }^{109}$. Indicará que lo prehistórico significa genérico, o sea, entendemos que se refiere a un conjunto de elementos con las mismas características. La cultura es en este punto comprendida como actividad genérica, y señalará que la misma ha desaparecido hace mucho tiempo y que todavía no ha comenzado. Asimismo, señala que el nombre de este período, como "primitivo" o "prehistórico" le viene dado por Nietzsche porque precede a la historia universal y se vincula con una moralidad o eticidad de las costumbres. De este modo, comprende que la vinculación de la cultura con los períodos se decide en base a una moral imperante. Así, entendemos que es el tipo de moral el que va a diferenciar cada período.

Luego, señalará que la moralidad de las costumbres es el movimiento de la cultura, la cual no se separa de todo tipo de medios de violencias que sirven para adiestrar al hombre. "Nietzsche llama al movimiento de la cultura «moralidad de las costumbres»; ésta no es separable de las picotas, de las torturas, de los atroces medios que sirven para adiestrar al hombre..." ${ }^{110}$ De este modo, podemos observar cómo este punto de vista de la cultura mantiene un vínculo con la definición general que dábamos anteriormente. Así, la considera como un conjunto de fenómenos vinculados a violencias que logra a través de medios adiestrar y seleccionar al hombre. Por otro lado, ya notamos la fuerte vinculación entre el concepto de cultura y la formación de sujetos.

Más adelante, indicará que en este adiestramiento violento se distinguen dos elementos, los cuales no deben confundirse a pesar de que en la historia son inseparables: el primero, todo aquello a lo que se obedece, un pueblo, una raza, un Estado, una clase, una iglesia, etc., la presión de estos sobre los individuos que quiere asimilar, es siempre histórico, arbitrario, grotesco, estúpido y limitado; y segundo, el hecho de obedecer a algo, por el hecho mismo de obedecer (obedecer la ley por la ley misma, poco importa su contenido) que es la actividad de la especie humana ejercida

\footnotetext{
109 "La cultura considerada desde su punto de vista prehistórico" Ibídem. ${ }^{110}$ Ibídem.
} 
sobre el individuo como tal. Asimismo, identifica esta obediencia hacia la ley con una fuerza activa (una actividad) que actúa sobre el hombre y que tiene como meta adiestrarlo. "Obedecer a la ley porque es la ley: la forma de la ley significa que cierta actividad, cierta fuerza activa, viene ejercida sobre el hombre y se fija por tarea adiestrarlo." ${ }^{111}$ Asimismo, señala que cualquier ley histórica (su contenido) es arbitraria, pero la ley de obedecer leyes es prehistórica, genérica.

De esta forma, el primer elemento no sería considerado desde el punto de vista prehistórico ya que es destacado como histórico, pero sí el segundo, ya que señala que es genérico y prehistórico. ${ }^{112}$ Asimismo, también se vincula a la actividad, la cual señalábamos al comienzo se relaciona con dicho período.

Luego, hablará de la cultura en relación a la justicia y sus medios. Asimismo, como ya pudimos observar, los medios de la misma se vinculan con las violencias, castigos, suplicios, a través de los cuales se logra activar las fuerzas reactivas. “...cuántos suplicios son necesarios para adiestrar a las fuerzas reactivas, para obligarlas a ser activadas." ${ }^{113}$ Así, señala que el método de la cultura siempre ha sido hacer del dolor un equivalente de un olvido, de una pena causada o de una promesa no cumplida.

Luego, señala que para comprender la ecuación de la justicia que se planteaba anteriormente (pena infligida $=$ dolor sufrido) se debe agregar un tercer término: el placer que se experimenta al infligir o contemplar dolor. $Y$ este sentido externo del dolor, remite a un punto de vista activo, a fuerzas activas que tienen como función adiestrar las reactivas. "Pero este tercer término, sentido externo del dolor, tiene también un origen totalmente distinto de la venganza o de la reacción: remite a un punto de vista activo, a fuerzas activas, que tienen como función y como placer el adiestrar las fuerzas reactivas." ${ }^{114}$ Así, la justicia debe comprenderse como la actividad genérica que adiestra las fuerzas reactivas, las hace aptas de ser activadas.

Continuando con la justicia, indica que la misma no tiene su origen en el resentimiento ni la mala conciencia, las cuales están vinculadas a las fuerzas reactivas.

\footnotetext{
111 Ibídem.

${ }^{112}$ Cfr. Ibídem.

113 Ibídem.

${ }^{114}$ Ibíd., p. 191
} 
De esto se desprende que el castigo no produce en el hombre el sentimiento de culpa. "El castigo no tiene la propiedad de despertar en el culpable el sentimiento de la culpa." ${ }^{\prime 15}$ De esta forma, la justicia desde el punto de vista prehistórico, es activa, que no esconde un resentimiento ni despierta en el hombre la mala conciencia o culpa.

Ahora, daremos un repaso general de la cultura desde el punto de vista prehistórico para lograr una mayor comprensión de los elementos dados. En principio, Deleuze señala que este punto de vista expresa la actividad genérica. Asimismo, indica que lo prehistórico tiene que ver con la moralidad o eticidad de las costumbres características de las culturas más primitivas. Luego, señalábamos que el pensador francés comprendía a la moralidad de las costumbres como el movimiento de la cultura, que acarrea el adiestramiento y selección del hombre.

Asimismo, vimos que de este adiestramiento se desprendían dos elementos, de los cuales el segundo lo vinculábamos al punto de vista que estamos analizando. Así, este elemento señalaba que se obedecía la ley por la ley misma, lo que se vinculaba con la actividad del hombre. De esta manera, pudimos observar que este adiestramiento activo hacía posible la activación de las fuerzas reactivas.

Luego, en relación a los medios y la justicia, destacábamos la violencia y los castigos como formas de hacer justicia ante un dolor sufrido, teniendo en cuenta el placer como algo activo. De este modo, se comprende a la justicia de manera activa, separándola de la mala conciencia y el resentimiento, las cuales se vinculan con la reactividad.

\subsection{La cultura desde la historia.}

En el caso de la cultura en la historia recibe un sentido muy diferente a su esencia al ser capturada por diversas fuerzas. ${ }^{116}$ Sin embargo, la actividad genérica en la historia no se separa de un movimiento que la desnaturaliza y desnaturaliza su producto. Así, el punto de vista prehistórico se desnaturaliza. La historia es la propia desnaturalización, es la "degeneración de la cultura". En este momento conviene

\footnotetext{
${ }^{115}$ Ibídem.

116 "La cultura en la historia recibe un sentido muy diferente de su propia esencia, al ser capturada por fuerzas..." Ibíd., p. 194.
} 
recordar la distinción entre los dos elementos del adiestramiento de la cultura en el punto anterior y su carácter inseparable.

De esta forma, indica que en lugar de una actividad genérica, la historia da a conocer, razas, pueblos, clases, Estados, Iglesias. "Aún más, la historia es esta propia desnaturalización, se confunde con la «degeneración de la cultura». En vez de la actividad genérica, la historia nos presenta razas, pueblos, clases, Iglesias y Estados." ${ }^{117}$ De este modo, podemos señalar esto como el aspecto de adiestramiento de la cultura desde la historia. Así, indica que sobre la actividad genérica se reúnen organizaciones sociales, asociaciones, comunidades de carácter reactivo, elementos que vienen a recubrirla y absorberla. De este modo, a través de la actividad genérica las fuerzas reactivas forman colectividades.

Entonces, en vez de la justicia y su autodestrucción, la historia nos presenta sociedades que no quieren desaparecer, que no conciben nada superior a ellas mismas. Así, las leyes en la historia se confunden con el contenido de las mismas, un contenido reactivo que le impide desaparecer excepto en beneficio de otros contenidos. "La ley se confunde en la historia con el contenido que la determina, contenido reactivo que la lastra y le impide desaparecer, excepto en provecho de otros contenidos, más estúpidos y más pesantes." ${ }^{118}$

Por otro lado, la selección y la jerarquía se invierten en la historia, convirtiéndose en medios para prolongar la vida reactiva, terminando por ser diferentes que desde el punto de vista de la actividad. De este modo, el adiestramiento sirve para que triunfen las fuerzas reactivas. Así, señalará que la historia aparecerá como el acto por el cual las fuerzas reactivas se apoderan de la cultura o la desvían de su provecho. De este modo, el triunfo de las fuerzas reactivas es el principio y sentido de la historia universal. "El triunfo de las fuerzas reactivas no es un accidente en la historia, sino el principio y el sentido de «la historia universal»."119

Luego, Deleuze se detendrá a explicar por qué y cómo la cultura pasa al servicio de las fuerzas reactivas. Asimismo, vuelve a señalar que la cultura no se puede separar

\footnotetext{
117 Ibídem.

${ }^{118}$ Ibídem.

${ }^{119}$ Ibíd., p. 195
} 
del movimiento que la desnaturaliza poniéndola al servicio de las fuerzas reactivas, no se separa de la historia (los dos elementos del adiestramiento). Y, en el proceso de adiestramiento, durante el cual la cultura intenta activar las fuerzas reactivas, este se da de manera ambigua permitiendo a las fuerzas reactivas ponerse al servicio de otras de su misma clase, dándole una apariencia de actividad, formando una ficción que prevalece sobre las activas.

La actividad de la cultura se propone adiestrar al hombre, es decir, darle las fuerzas reactivas aptas para servir, para ser activadas. Pero, durante el adiestramiento, esta aptitud para servir es profundamente ambigua. Ya que permite al mismo tiempo a las fuerzas reactivas ponerse al servicio de otras fuerzas reactivas, dar a éstas una apariencia de actividad, una apariencia de justicia, formar con ellas una ficción que prevalece sobre las fuerzas activas. ${ }^{120}$

De esta forma, las fuerzas reactivas se incorporan a la actividad genérica y desvían su sentido, y gracias al adiestramiento, podrán asociarse y formar una reacción colectiva usurpando la actividad genérica.

En conclusión, la cultura desde este punto de vista, desnaturaliza a la cultura de la prehistoria y su producto. Ya que como pudimos observar, los elementos de adiestramiento son inseparables. Así, la historia nos presenta sociedades que no conocen nada superior a ellas mismas, a sus leyes. De este modo, se anticipa que desde la historia lo que interesa es el contenido de dichas leyes (primer elemento de adiestramiento). Asimismo, se comprende a este contenido como algo reactivo. Por lo que podemos entender que constituirán una justicia reactiva.

Por otro lado, hemos señalado que la jerarquía y la selección se invierten en relación al punto de vista de la prehistoria. Y lo hacen en provecho de las fuerzas reactivas. Así, la historia aparece como el medio por el cual triunfan las fuerzas reactivas apoderándose de la cultura.

${ }^{120}$ Ibíd., p. 197 
Asimismo, explicábamos cómo se daba este proceso de desnaturalización, indicando que el adiestramiento se da de manera ambigua, provocando que las fuerzas reactivas se agrupen en base a una ficción y triunfen dando la apariencia de actividad.

\subsection{Clave para la distinción entre los tipos de culturas.}

Según lo desarrollado hasta el momento entendemos que ambos puntos de vista de la cultura se distinguen en relación a las fuerzas activas o reactivas, su triunfo, y responsabilidad. Así, el punto de vista prehistórico genera responsabilidad por las fuerzas reactivas y se caracteriza por la actividad; y el punto de vista histórico es el triunfo de las fuerzas reactivas y genera una responsabilidad o culpabilidad por la actividad. De este modo, cada uno de los puntos que dimos en relación a ambas se vinculaba a la actividad o reactividad respectivamente. Sin embargo, como señalábamos, la distinción entre puntos de vistas se asienta en una diferencia entre dos tipos de moral. Pero, desde nuestra posición, entendemos que las fuerzas activas y reactivas toman un rol central en la distinción de estos tipos de moral, comprendiéndolas como fuerzas constitutivas de la cultura. Asimismo, nuestra afirmación se sostiene por el hecho de que el autor francés en otros pasajes de su obra vincula a la cultura con otros elementos que no necesariamente se vincularían a la moral, ya lo veremos más adelante.

Así, si comprendemos que la diferencia entre las cultura no solamente se resume a una distinción de tipo moral y consideramos fundamental la distinción entre fuerzas activas y reactivas entonces para continuar esta diferenciación de las culturas, iremos observando qué elementos y cómo se vinculan con la actividad o la reactividad respectivamente a lo largo del texto deleuziano, afirmando por medio de estas un vínculo con la cultura. De este modo, afirmamos la existencia de una cultura como actividad genérica y otra como triunfo de la reactividad, las cuales incluirían los demás elementos. ${ }^{121}$

\footnotetext{
${ }^{121}$ También debemos incluir a la ciencia, religión, la historia, y lenguaje como elementos de la cultura, los cuales no serán señalados por una cuestión de extensión del trabajo, pero se pueden hallar una clara relación entre estos y las fuerzas activas y reactivas. Así también, señalamos que son destacados como los que vamos a desarrollar ya que el pensador no realiza una relación entre estos y la producción de subjetividades e instituciones lo que es de nuestro interés. Sin embargo, no desconocemos su carácter formador de sujetos ya que como partes de la cultura se vinculan con el adiestramiento y selección se hombres.
} 


\subsubsection{La filosofía: su vínculo con las fuerzas y la cultura.}

En principio destaca a la filosofía como lugar de expresión del triunfo de las fuerzas reactivas. Así, señala que la crítica a Sócrates se debe a que ha puesto el pensamiento al servicio de la vida. De modo que cuando Sócrates pone a la vida al servicio del conocimiento, toda la vida se vuelve reactiva. Pero cuando pone el pensamiento al servicio de la vida hay que entender que la vida reactiva en particular se convierte en modelo de toda la vida y del mismo pensamiento. “...cuando Sócrates pone la vida al servicio del conocimiento, hay que entender a toda la vida que, a partir de ahí, se convierte en reactiva; pero cuando pone el pensamiento al servicio de la vida hay que entender esta vida reactiva en particular, que se convierte en el modelo de toda la vida y del mismo pensamiento."122

Por otra parte, señala que la crítica de Kant se convierte en una política del compromiso. Es Kant quien empieza creyendo en aquello mismo que critica. Por ello, la crítica no va a decir nada mientras señale que los "verdaderos conocimientos" se burlan de los "falsos", no habrá hecho nada mientras alcance su propia "verdad". Por esto, la crítica al conocimiento no puede ser al conocimiento "falso", sino al conocimiento mismo, al verdadero conocimiento. "Siempre que Nietzsche denuncia la virtud, lo que denuncia no son las falsas virtudes, ni los que se sirven de la virtud como de una máscara. Es la propia virtud en sí misma, es decir: la, pequeñez de la verdadera virtud, la increíble mediocridad de la verdadera moral, la bajeza de sus auténticos valores..."123 De este modo, se observa una crítica a la voluntad de verdad.

En este punto debemos destacar la vinculación entre los defensores de la voluntad de verdad y los negadores de vida o nihilistas, así como los ascetas, que nuevamente vuelven a relacionarse con la reactividad. Esto dice en relación a los que quieren la voluntad de verdad o niegan la vida: "El que reniega de la vida es también el que quiere una vida disminuida, su vida degenerada y disminuida [...] Es la voluntad de la nada la que sólo soporta la vida bajo su forma reactiva. Ella es quien utiliza las fuerzas reactivas como medio por el que la vida debe contradecirse, negarse, aniquilarse [...] La voluntad de la nada y las fuerzas reactivas, éstos son los dos

\footnotetext{
${ }^{122}$ Ibíd., p. 142

${ }^{123}$ Ibíd., p. 128
} 
elementos constituyentes del ideal ascético." ${ }^{124}$ De esta forma, aquí podemos observar cómo la crítica a la filosofía es también una crítica a su voluntad de verdad, que decanta en una crítica a la voluntad de la nada, a las fuerzas reactivas y al ideal ascético.

Continuando con su crítica a los filósofos, indica que esta idea de alcanzar un "conocimiento verdadero" se encuentra dentro de lo que él denomina "imagen dogmática del pensamiento"125. En ella señala que se ocultan los poderes establecidos que se expresan a través de verdades. Asimismo, señala a Kant y a Hegel, pero a los filósofos en general, como personajes históricos que contribuyeron a defender esta imagen y con ella ayudaron a confundir los fines de la cultura con la moral, la religión, el Estado. "Y desde Kant hasta Hegel, en suma, el filósofo se ha comportado como un personaje civil y piadoso, que se complacía en confundir los fines de la cultura con el bien de la religión, de la moral o del Estado."126 Aquí se vincula claramente la filosofía con una cultura reactiva. Si recordamos que desde el segundo elemento de adiestramiento es donde se confunde a la cultura con los fines del Estado, la religión, etc. "La imagen del filósofo se oscurece debido a todos sus disfraces necesarios, pero también debido a todas las traiciones que hacen de él el filósofo de la religión, el filósofo del Estado, el coleccionista de los valores en curso, el funcionario de la historia." 127

De este modo, establece claras relaciones entre la filosofía, el ideal ascético, la voluntad de verdad, la voluntad de la nada, las fuerzas reactivas, etc. Lo que nos permite pensar en un tipo de filosofía reactiva, mediante la cual se expresan dichas fuerzas. Así también, nos permite vincular a la filosofía con una cultura reactiva, como un elemento más de dicha cultura. Asimismo, también podemos relacionar la cultura reactiva con el ideal ascético, la voluntad de la nada y la voluntad de verdad.

Por otro lado, dejando de lado esta filosofía emparentada con la reactividad, Deleuze también presenta la idea de una nueva filosofía que afirma una "nueva imagen del pensamiento" y a la vida en su totalidad. Asimismo, esta filosofía sirve para

\footnotetext{
${ }^{124}$ Ibíd., p. 137

${ }^{125}$ Ver: Ibíd., p. 146

${ }^{126}$ Ibíd., p. 149

${ }^{127}$ Ibíd., p. 151
} 
desmitificar a los defensores de la "imagen dogmática del pensamiento". Así, se pretende, desde esta filosofía defendida por Deleuze, hacer del pensamiento algo afirmativo. En este punto vincula al pensamiento con una violencia de adiestramiento y selección (características de la cultura). Así, una filosofía activa que afirme la vida, forma parte de la cultura. "Debe ejercerse una violencia sobre él en tanto que pensamiento, un poder debe obligarle a pensar, debe lanzarle hacia un devenir-activo. Esta coacción, este adiestramiento, es lo que Nietzsche llama «Cultura» [...] Expresa la violencia de las fuerzas que se apoderan del pensamiento para hacer de él algo activo, afirmativo."128 Es importante señalar aquí, que por pasajes como estos, afirmábamos que la noción de cultura no se limitaba exclusivamente a una distinción de dos tipos de moral.

De esta manera, se comprende que no se debe confundir a los fines de la cultura con los del Estado, la religión o los valores en curso, tal como lo hacen los demás filósofos criticados por Deleuze. Quedando clara la desvinculación de este nuevo tipo de filosofía de la cultura reactiva. De hecho, señalará que el fin de la cultura como actividad genérica, o sea, desde el punto de vista prehistórico, es crear filósofos y artistas. "La actividad genérica de la cultura tiene un objetivo final: formar al artista, al filósofo. Toda su violencia selectiva se halla al servicio de este fin..." ${ }^{129}$

Sin embargo, si bien señala a los filósofos y artistas como fines de la cultura desde el punto de vista prehistórico, lo que podría llevarnos a pensar que pertenecen al mismo, más adelante veremos que los fines de la cultura no deben confundirse con los medios de esta. De modo tal que veremos después de qué modo deberíamos comprender a los filósofos, los artistas e incluso también a los científicos.

\subsubsection{La moral: su vínculo con las fuerzas y la cultura.}

Si bien ya hemos señalado que la distinción entre dos tipos de moral determinaba la división entre el punto de vista histórico y el prehistórico, en este punto pretendemos ampliar dichas diferencias para alcanzar una mayor comprensión de los contenidos e incorporación de nuevos elementos.

\footnotetext{
${ }^{128}$ Ibíd., p. 153

${ }^{129}$ Ibíd., p. 154
} 
Así, cuando se detiene Deleuze a hablar sobre qué es lo bueno y qué lo malo, destaca dos fórmulas: la primera dice: yo soy bueno, luego tú eres malo; la segunda dice: tú eres malo, luego yo soy bueno. Si se analizan estas dos posiciones se observaran una pluralidad de sentidos de los términos "buenos", "malos" e incluso el término "luego".

El de la primera fórmula se llama a sí mismo bueno en la medida que actúa, afirma y goza. Por ello, se dice que el que se afirma y actúa es al mismo tiempo el que "es". Y en este principio no interviene ninguna comparación. Así, que otros sean malos en la medida que no actúen no gocen, etc., es una consecuencia secundaria. De esta forma, bueno en primera instancia se designa al "señor" y malo al "esclavo". "¿quién es aquél que empieza diciendo: «Soy bueno»? Ciertamente no es el que se compara a los demás, ni el que compara sus acciones y sus obras con valores superiores o trascendentes: no empezaría... El que dice: «Soy bueno» no espera ser llamado bueno. Se llama así, se nombra y se denomina así, en la misma medida en que actúa, afirma y goza." 130

En este punto, podemos vincular esta primer formula con la moral de las costumbres característica del punto de vista prehistórico debido a que se trata de una moral activa. Asimismo, señala Deleuze, que aquí no se encuentra el menor matiz de una "moral", se trata más bien de una "ética". También, en esta primera fórmula, la palabra "luego" indica una conclusión negativa, y esta se presenta como consecuencia de una afirmación. De este modo, existe una doble afirmación en las premisas, para llegar a la conclusión de algo negativo, que no es esencial y apenas tiene importancia, solo la tiene en el sentido en que sirve para aumentar el contenido de la acción, la afirmación y el goce. De esta forma, el bueno busca su antípoda solo para afirmarse a sí mismo. Este es el estatuto de la agresividad: lo negativo como conclusión de las premisas, lo negativo como producto de la actividad. Aquí también aparece la actividad vinculada con esta primera fórmula y por lo tanto, con una cultura como actividad genérica. Asimismo, también debemos agregar el elemento de la afirmación, como una característica más de la cultura activa.

${ }^{130}$ Ibíd., p. 169 
Por otra parte, en la segunda fórmula, lo negativo pasa a las premisas y lo positivo es concebido como una conclusión. Lo negativo es lo que contiene lo esencial, y lo positivo solo existe mediante la negación. Así, para obtener una conclusión aparentemente positiva se debe partir de premisas de resentimiento, de negación, de nihilismo. "«Tú eres malo, luego yo soy bueno». En esta fórmula quien habla es el esclavo [...] Y el bueno, ahora, es el que contiene su actuación: y es bueno precisamente por esto, porque remite cualquier acción al punto de vista del que no actúa, al punto de vista del que experimenta sus consecuencias..." ${ }^{131}$ Estos últimos elementos como el resentimiento, negación, la no actuación, etc., vincularían esta segunda fórmula a una moral más característica de la cultura reactiva.

Luego, señala que desde esta segunda fórmula también se crean valores. De este modo, el bueno es ahora el que contiene su actuación, remite cualquier acción al punto de vista del que no actúa, de un tercero "divino" que escruta sus intenciones. Bueno es el que no le hace daño a nadie, no ataca, que no actúa, etc. Recordemos que el punto de vista histórico, generaba responsabilidad por su acción, aquí también se destaca que debe contener su acción. Finalmente, Deleuze señala a esto como el origen del bien y el mal: la determinación "ética", la de lo bueno y lo malo, es desplazada por el "juicio moral". Así, el bueno de la ética (cultura como actividad genérica) se ha convertido en el malo de la moral y viceversa.

Más adelante, señalará que la moral de los esclavos se asienta en una ficción ya que separa a las fuerzas activas de lo que pueden, logrando el triunfo de las reactivas. "El paralogismo del resentimiento se basa en esto: La ficción de una fuerza separada de lo que puede. El triunfo de las fuerzas reactivas se debe a esta ficción..." ${ }^{132}$ Aquí nuevamente se detiene en la distinción entre fuerzas y dos tipos de moral, o como el mismo la llama una moral y otra ética. Asimismo, vincula a la moral con una ficción originaria que permite el triunfo de la reactividad.

Finalmente, en cuanto a la moral debemos observar que se divide en dos tipos dependiendo de las fuerzas y por lo tanto, los tipos de cultura. Así, la moral característica de una cultura activa, se caracteriza por la afirmación, la actividad, por

\footnotetext{
${ }^{131}$ Ibíd., p. 171

132 Ibíd., p. 173
} 
las costumbres. Asimismo, Deleuze no la denomina moral, sino "ética". Y, en el caso de la moral de una cultura reactiva, se caracteriza por la negación, la pasividad, el resentimiento, el ideal ascético, la voluntad de la nada, la ficción; y es llamada moral propiamente dicha.

\subsection{Consideraciones finales con respecto al concepto de cultura.}

De esta forma, de manera general el pensador francés define a la cultura como adiestramiento y selección. Asimismo, señala que esto se lleva a cabo a través de un conjunto de elementos. Por otra parte, entendemos que diferencia dos tipos de cultura, una como actividad genérica, la cual denominamos de esta manera por vincularse a las fuerzas activas; y otra como triunfo de las fuerzas reactivas, por vincularse a dichas fuerzas. Asimismo, cabe señalar que el mismo autor indica que esta distinción no se da en la realidad, donde ambos elementos se encuentran relacionados. "La actividad genérica en la historia no se separa de un movimiento que la desnaturaliza, y que desnaturaliza su producto." ${ }^{133}$ Por ello, entendemos que refiere a "puntos de vista" y no períodos históricos.

Partiendo de esta distinción basal entre tipos de fuerzas hemos podido diferenciar varios elementos que deberían comprenderse dentro de la cultura. Así, pudimos ver, en principio, que la distinción entre los puntos de vista prehistórico e histórico se fundamenta en una distinción de dos tipos de moral. Asimismo, observamos una moral vinculada a las fuerzas activas, o ética para el pensador francés, y otra moral emparentada con la reactividad, o juicios morales propiamente dichos.

De esta forma, hemos distinguido, también; una filosofía activa y reactiva; una ciencia activa y reactiva; una religión activa y reactiva; un lenguaje activo y reactivo; y una historia activa y reactiva. Sin embargo, todavía no podemos afirmar que los elementos activos se vinculen directamente con una cultura como actividad genérica (ya veremos esto en el análisis de las subjetividades). Asimismo, si se observa bien la relación de los puntos reactivos con la cultura de la historia.

133 Ibíd., p. 194 
Además, cabe destacar en relación a esto último, nuestra distinción entre una cultura como medio y una cultura como fin. De este modo, tenemos una cultura como medio, que se emparenta con la cultura reactiva y la cultura como actividad genérica, y una cultura como fin, que se vincula con una filosofía activa y el arte.

\section{La noción de fuerzas en Deleuze y su vínculo con las subjetividades.}

En principio comenzaremos con el análisis de tipo topológico, para luego pasar al aspecto tipológico. Así, cuando el pensador francés habla de las fuerzas activas y reactivas, señala primeramente que las segundas tienen siempre el papel de limitar a las primeras. "En estado normal o sano, las fuerzas reactivas tienen siempre el papel de limitar la acción. La dividen, la atrasan o la impiden en función de otra acción de la cual padecemos el efecto." ${ }^{134}$ Sin embargo, en el caso de las activas estas hacen explotar las primeras formando una réplica: por ello se dice que la verdadera reacción es la de la acción. O sea, hay dos tipos de reacción, la que deviene de una acción o la que se origina en una ficción. De este modo, se comprende que el "tipo activo" no contiene exclusivamente a las fuerzas activas, sino que además expresa la relación entre una reacción que retarda la acción y una acción que precipita la reacción. Por ello, se puede decir que el tipo activo engloba a las fuerzas reactivas, pero en tal estado que se definen por un poder de obedecer o ser activadas. Más adelante veremos a que se refiere por "tipo" en el análisis tipológico.

De esta forma, se advierte que una reacción no basta para provocar el resentimiento. Este se hace presente cuando las fuerzas reactivas prevalecen sobre las activas y solo prevalecen cuando dejan de ser activadas. "A partir de aquí se comprende que una reacción no basta para provocar un resentimiento. El resentimiento designa un tipo en el que las fuerzas reactivas prevalecen sobre las fuerzas activas. ${ }^{135}$ Se dice que este triunfo de las reactivas se da porque escapan a su acción. Así, a través del resentimiento la reacción deja de ser activada para convertirse en algo sentido. De esta manera, vemos las relaciones entre el resentimiento y la reactividad que señalábamos cuando analizábamos la cultura reactiva.

\footnotetext{
${ }^{134}$ Ibíd., p. 157

${ }^{135}$ Ibíd., p. 157-158
} 
Ahora veremos la manera en que actúan estas fuerzas sobre los sujetos, haciendo mención a lo que se denomina como "aparato reactivo". El mismo se conforma por dos sistemas: el consciente y el inconsciente. "Estos dos sistemas o registros corresponden a la distinción de la conciencia y del inconsciente."136 Asimismo, el consciente reactivo se define por las trazas mnémicas que son huellas duraderas que implican la imposibilidad puramente pasiva de sustraerse a la impresión una vez recibida. Aquí, las fuerzas reactivas realizan su tarea: fijarse a la huella indeleble, investir la traza. Sin embargo, una adaptación no sería posible si el aparato reactivo no dispusiera de otro sistema de fuerzas. De este modo, en el otro sistema, el inconsciente, la reacción ya no es más a las trazas, sino una reacción a la excitación presente o imagen directa del objeto. Este segundo tipo de fuerzas no está separado de la consciencia. Se presenta como una corteza renovada para la receptividad siempre nueva. ${ }^{137}$ Asimismo, debemos pensar a ambos sistemas como inseparables. Luego, señala que este segundo sistema de fuerzas nos muestra bajo qué forma puede ser activada la reacción: cuando las fuerzas reactivas toman por objeto la excitación en la conciencia, entonces la reacción correspondiente se convierte en algo activado.

Pero, hay que impedir que las trazas invadan la consciencia, para ello una fuerza activa, distinta y delegada, debe apoyar la conciencia y reconstruir a cada instante su frescura. Y esta facultad activa supra-consciente es el olvido. "Una fuerza activa, distinta y delegada debe apoyar la conciencia y reconstituir en cada instante su frescura, su fluidez, su elemento químico móvil y ligero." ${ }^{138}$ Deleuze define al olvido como una facultad de entorpecimiento, un aparato de amortiguamiento, una fuerza plástica regenerativa y curativa. Luego, indica que al mismo tiempo que la reacción se convierte en algo activado al tomar por objeto la excitación de la consciencia, la reacción permanece en el inconsciente como algo insensible. $Y$ es por esto que si lo que absorbemos se hace tan poco patente a nuestra conciencia, se deduce que ninguna serenidad, ninguna felicidad, ninguna esperanza, ningún orgullo, ningún goce

\footnotetext{
${ }^{136}$ Ibíd., p. 158

137 "Esta segunda especie de fuerzas reactivas no se separa de la conciencia; corteza siempre renovada por una receptividad siempre fresca, medio en el que «de nuevo hay sitio para cosas nuevas»." Ibíd., p. 159 ${ }^{138}$ Ibídem.
} 
del estado presente podría existir sin la facultad del olvido. Además, agrega el autor que el olvido sirve de guardián, de vigilante para que no haya confusión entre los dos sistemas del aparato reactivo. "Pero obsérvese la particular situación de esta facultad: fuerza activa, es delegada por la actividad al lado de las fuerzas reactivas. Sirve de «guardián» o de «vigilante»; impidiendo la confusión de los dos sistemas del aparato reactivo." ${ }^{139}$ De este modo, la fuerza activa tiene una actividad enteramente funcional, si bien emana de la actividad pero es abstraída de ella, por eso debe tomar constantemente prestada la energía de la segunda especie de fuerzas reactivas, y hacer suya esta energía para dársela a la consciencia. De esta forma, se comprende cómo está siempre sometida a variaciones, a fracasos y a turbaciones puramente funcionales.

Si se diera el deterioro en la facultad del olvido, lo que sucedería seria que la excitación comenzaría a confundirse con la traza en el inconsciente, e inversamente la reacción de las trazas sube por la conciencia hasta invadirla. "Supongamos un desfallecimiento de la facultad del olvido: la cera de la conciencia está como endurecida, la excitación tiende a confundirse con su traza en el inconsciente, e inversamente, la reacción a las trazas sube por la conciencia hasta invadirla." ${ }^{140} \mathrm{De}$ este modo, la reacción de las trazas se convierte en algo sensible, la reacción de la excitación deja de ser activada. Y, al no poder activar a las fuerzas reactivas, las fuerzas activas están privadas de sus condiciones materiales de ejercicio. Por ello, se dice que están separadas de lo que pueden. Así, se comprende que el triunfo de las fuerzas reactivas se da cuando las trazas ocupan el lugar de las excitaciones en el aparato reactivo, la propia reacción ocupa el lugar de la acción. "Finalmente vemos de qué forma las fuerzas reactivas prevalecen sobre las fuerzas activas: cuando la traza ocupa el lugar de la excitación en el aparato reactivo, la propia reacción ocupa el lugar de la acción, la reacción prevalece sobre la acción." ${ }^{141}$ Este desfallecimiento de la facultad de olvido, proviene del hecho de que ya no encuentra suficiente energía en las fuerzas reactivas para rechazar a otra especie y renovar la conciencia.

\footnotetext{
${ }^{139}$ Ibíd., p. 160

${ }^{140}$ Ibíd., p. $160-161$

${ }^{141}$ Ibíd., p. 161
} 
Luego, se centrará en el resentimiento como una reacción que se convierte en sensible y deja de ser activada. "Volvemos a hallar la definición del resentimiento: el resentimiento es una reacción que simultáneamente se convierte en sensible y deja de ser activada." En un comienzo señala que el primer aspecto del resentimiento es topológico, ya que es un desplazamiento de lugar lo que constituye el resentimiento. Así, lo que caracteriza al resentimiento es la invasión de la conciencia por trazas mnémicas, subidas en la conciencia en la propia memoria. En este punto, aclara que existen dos memorias, si nos quedamos en la primera memoria, estamos en el umbral del principio puro del resentimiento. Así, el hombre de resentimiento confunde la huella, la traza, con la excitación y esto le impide activar su reacción.

Pasando ahora al análisis tipológico el pensador francés comprende por tipo lo siguiente: una realidad a la vez, biológica, física, histórica, social, política. ${ }^{142}$ De esta forma señala que cuando las fuerzas reactivas triunfan sobre las activas por esto que se dio, constituyen las mismas un "tipo". Y el principal síntoma de ese tipo es una prodigiosa memoria. De esta forma, se comprende la naturaleza reactiva que tiene esta facultad de no olvidar. Así, para Deleuze, lo que se debe tener en cuenta es la determinada relación del sujeto con las fuerzas de diferente naturaleza que lo componen, o sea, un tipo.

En el caso del llamado hombre de resentimiento solo utiliza la fuerza total del propio sujeto, no la de la excitación recibida, para precisamente investir esta última por lo que es incapaz de actuar e incluso reaccionar ante la excitación. De este modo, en virtud de su tipo, el hombre de resentimiento no reacciona, su reacción no acaba nunca, es sentida en lugar de ser activada. De esta forma, le echa la culpa a un objeto o ser, del cual hay que vengarse, haciendo al objeto responsable de su propia impotencia para investir algo que no sean huellas, impotencia cualitativa o típica. "En virtud de su tipo, el hombre del resentimiento no «reacciona»: su reacción no termina nunca, es sentida en lugar de ser activada. Así, le echa la culpa a su objeto sea cual sea, como a un objeto del que hay que vengarse, al que hay que hacer pagar precisamente

142 “Un tipo, en efecto, es una realidad a la vez biológica, física, histórica, social y política.” Ibíd., p. 163 
este infinito atraso." ${ }^{143}$ De esta forma, el hombre de resentimiento es un ser doloroso, guarda con él rápidamente cualquier excitación, y el peso de las huellas que lo invaden son otros tantos crueles sufrimientos. Es venenosa y despreciativa, porque echa la culpa al objeto para compensar su propia impotencia en sustraerse a las huellas de su correspondiente excitación. Por ello, la venganza del resentimiento, cuando se lleva a cabo, no deja de ser nunca imaginaria y simbólica en su origen. "Por eso la venganza del resentimiento, incluso cuando se lleva a cabo, no deja de ser menos "espiritual», imaginaria y simbólica en su principio."144

Luego, cuando habla del espíritu de venganza, señala que el espíritu es el medio para la venganza, y no se debe entender como el deseo de venganza. Y con medio se refiere a que es la forma por la cual la venganza invierte la relación normal de las fuerzas activas y reactivas. De esta forma, el triunfo del espíritu de venganza es el triunfo del resentimiento, la sublevación del esclavo. "Por eso, en sí el resentimiento es ya una sublevación, es ya el triunfo de esta sublevación. El resentimiento es el triunfo del débil como tal, la sublevación de los esclavos y su victoria en tanto que esclavos." ${ }^{145}$ Asimismo, es en la victoria donde los esclavos forman un tipo.

Luego, Deleuze se detendrá en la memoria de las huellas, la cual para él es en sí misma odiosa, incluso en sus deseos más tiernos se oculta el odio y la venganza. Así, los memoriosos, suelen disfrazar este odio con una sutil operación de reprocharse a sí mismos todo lo que de hecho reprochan al ser del que fingen apreciar el recuerdo. "Los rumiantes de la memoria suelen disfrazar este odio con una sutil operación, que consiste en reprocharse a sí mismos todo lo que de hecho reprochan al ser del que fingen apreciar el recuerdo." ${ }^{146}$ Luego, indica que para él lo más sorprendente del hombre de resentimiento es su capacidad despreciativa. Así, no respeta a sus amigos o enemigos como tampoco la causa de sus desgracias. De este modo, el hombre del resentimiento hace del dolor algo mediocre recriminando y distribuyendo los errores, haciendo de la desgracia la culpa de alguien. "Pero el hombre del resentimiento tiene

\footnotetext{
${ }^{143}$ Ibídem.

${ }^{144}$ Ibíd., p. 164

${ }^{145}$ Ibíd., p. 165

${ }^{146}$ Ibídem.
} 
que hacer del dolor una cosa mediocre, tiene que recriminar y distribuir los errores: su tendencia a depreciar las causas, a hacer de la desgracia «la culpa de alguien»." 147

Por otro lado, el autor francés se refiere a la pasividad. Asimismo, indica que en el resentimiento, la felicidad aparece como algo pasivo, y esto quiere decir no-activo o reactivo. Así, pasivo debe comprenderse a la reacción en tanto que no es activada, y en ese momento se convierte en resentimiento. "Pasivo es únicamente la reacción en tanto que no es activada. Pasivo designa el triunfo de la reacción, el momento en que, dejando de ser activada, se convierte precisamente en un resentimiento." 148

Por otra parte, dice que el hombre de resentimiento es el hombre del beneficio y el provecho. De hecho, una de las razones por la que triunfó el resentimiento ha sido porque se instaló el beneficio, haciendo del provecho un pensamiento, un deseo, un sistema económico, social, teológico, etc. "Más aún, si el resentimiento ha podido imponerse en el mundo ha sido haciendo triunfar el beneficio, haciendo del provecho no sólo un deseo y un pensamiento, sino también un sistema económico, social, teológico, un sistema completo, un mecanismo divino." 149

Finalmente, se pregunta lo que quieren los hombres de resentimiento, indicando que se trata de señalar a alguien como malo, para poder llamarse a sí mismos buenos: esta es la fórmula elemental de este tipo de hombre de resentimiento, se traduce lo esencial del resentimiento desde el punto de vista tipológico, resumiendo todos los caracteres precedentes. "Adivinamos lo que quiere esta criatura del resentimiento: quiere que los otros sean malos, necesita que los demás sean malos para poder sentirse buena." ${ }^{150}$ Seguidamente, compara esta fórmula con la del señor: yo soy bueno, luego tú eres malo.

Por otra parte, en cuanto al tipo activo, lo vincula con "el señor" que nosotros lo veíamos emparentado a la eticidad de las costumbres. Asimismo indica que este tipo está definido por la capacidad de olvidar, a diferencia del esclavo y su relación con la memoria como ya lo habíamos señalado. "El tipo del señor (tipo activo) vendrá definido por la facultad de olvidar, así como por el poder de activar las reacciones. El

\footnotetext{
${ }^{147}$ Ibíd., p. 166

148 Ibídem.

${ }^{149}$ Ibíd., p. 167

${ }^{150}$ Ibíd., p. 168
} 
tipo del esclavo (tipo reactivo) vendrá definido por la prodigiosa memoria, por el poder del resentimiento..." ${ }^{\prime 151}$

De esta manera, pudimos observar cómo Deleuze distingue dos tipos, el activo y el reactivo. Asimismo, cada tipo se define por el tipo fuerzas que se apoderan de este. Por otro lado, pudimos observar de qué manera el tipo reactivo se vincula con el resentimiento, la pasividad y la memoria; el tipo activo con una actividad y facultad de olvido.

\subsubsection{El hombre activo y su vínculo con la cultura como actividad genérica.}

Como ya pudimos observar la cultura tiene como objetivo adiestrar y seleccionar al hombre. En cuanto a la actividad genérica indica que debe ser entendida como aquella que trata de producir un hábito en el hombre, de adiestrarlo, de que obedezca leyes, (tal como lo señala en el segundo elemento de adiestramiento que indicábamos en los análisis sobre la noción cultura). Asimismo, vimos que la cultura como actividad genérica intentaba activar las fuerzas reactivas, hacer un hombre capaz de activar sus fuerzas reactivas. "Adiestrar al hombre significa formarlo de tal manera que sea capaz de activar sus fuerzas reactivas." 152 En este punto ya podemos observar la vinculación entre este sujeto y el tipo activo, en el cual se produce una activación de las fuerzas reactivas.

Más adelante, señalará Deleuze que el objetivo de esta cultura es reforzar la conciencia, dotándola de una nueva facultad: la memoria. Pero esta memoria no es una memoria de las huellas, como en el tipo reactivo, es una memoria en función del futuro. "La cultura dota a la conciencia de una nueva facultad que en apariencia se opone a la facultad del olvido: la memoria. Pero la memoria de la que ahora se trata no

es la memoria de las huellas." ${ }^{153}$ Así, forja una facultad de prometer, de compromiso con el futuro, recuerdo del futuro. Aquí se enuncia el objetivo de la cultura como actividad genérica: hacer un hombre capaz de prometer. "Éste es precisamente el objeto selectivo de la cultura: formar un hombre capaz de prometer, o sea, de

\footnotetext{
151 Ibíd., p. 165

152 Ibíd., p. 188

153 Ibídem.
} 
disponer del futuro, un hombre libre y poderoso. Sólo un hombre así es activo; activa sus reacciones, todo en él es activo o activado."154

Por otra parte en cuanto a lo que veíamos de la justicia, entiende a esta como un medio de la cultura. Asimismo, señala que esta ecuación (pena infligida = dolor sufrido) determina la relación entre los hombres, una relación de acreedor-deudor, la más antigua relación incluso anterior a las organizaciones sociales. De este modo, la justicia es lo que responsabiliza al hombre de su deuda. De manera que la cultura trata de hacer al hombre responsable de su deuda, responsable de sus fuerzas reactivas. "El hombre que paga con su dolor la pena que inflige, el hombre considerado responsable de una deuda, el hombre tratado como responsable de sus fuerzas reactivas: éste es el medio puesto en marcha por la cultura para conseguir su objetivo." ${ }^{155}$ Finalmente, claramente enuncia al producto de la cultura como actividad genérica, como un hombre activo al vincularlo con este tipo de fuerzas que se expresan en "el pacer".

Y no se llegará a comprender nunca la cruel ecuación pena infligida $=$ dolor sufrido, si no se introduce un tercer término, el placer que se experimenta al infligir o contemplar un dolor. Pero este tercer término, sentido externo del dolor, tiene también un origen totalmente distinto de la venganza o de la reacción: remite a un punto de vista activo, a fuerzas activas, que tienen como función y como placer el adiestrar las fuerzas reactivas. La justicia es la actividad genérica que adiestra a las fuerzas reactivas del hombre, que las hace aptas para ser activadas y considera al hombre responsable de esta misma aptitud. ${ }^{156}$

Así, queda clara la vinculación entre el tipo activo y la cultura como actividad genérica, ya que el autor francés enuncia claramente el carácter formador de la cultura y su vínculo preciso con el tipo activo. Sin embargo, en cuanto a lo que denominábamos los otros elementos de la cultura, como ser religión, filosofía, ciencia, etc., todavía no estamos en condiciones de señalar su tipo y vinculación con esta cultura como actividad genérica.

\footnotetext{
${ }^{154}$ Ibíd., p. 189

155 Ibíd., p. 190

${ }^{156}$ Ibíd., p. 190-191
} 


\subsubsection{El hombre reactivo y su vínculo con la cultura reactiva.}

El autor francés también es muy claro con respecto a esta relación entre la cultura reactiva y la construcción de tipos reactivos. Así, enuncia que el producto de la cultura reactiva es el hombre domesticado, en el que se encuentra el famoso sentido de la historia. "Se utilizan procedimientos de adiestramiento pero para hacer del hombre un animal gregario, una criatura dócil y domesticada." ${ }^{157}$ Luego, señala que la selección se da para elegir a los débiles, a los esclavos, es un medio para conservar la vida reactiva. Asimismo, ya pudimos observar la vinculación que había entre los hombres de resentimiento y los esclavos. De modo tal que comprendemos que cuando se refiere a los hombres domesticados se refiere al tipo reactivo, como producto de la cultura reactiva.

Por otro lado, como ya observábamos en los análisis con respecto a la cultura y al inicio de las subjetividades, desde una cultura reactiva se invierte la jerarquía y por lo tanto, las fuerzas reactivas triunfan. De este modo, se genera en el hombre una responsabilidad por su actividad, ya no por su reactividad, como pasaba en la cultura como actividad genérica. Esto también lo observábamos vinculado al tipo reactivo, en el cual se le se destacaba el triunfo de las fuerzas reactivas y la responsabilidad sobre la actividad.

De esta manera, es clara la relación entre el hombre domesticado como producto de una cultura reactiva y el tipo reactivo enunciado por Deleuze. Sin embargo, más adelante veremos qué tipo de relación guarda entre cada uno de los elementos de la cultura que señalábamos anteriormente.

\subsubsection{El elemento posthistórico de la cultura.}

Deleuze indicará que el producto de la cultura desde el punto de vista prehistórico es: el hombre libre, responsable, capaz de prometer; es diferente al elemento posthistórico del hombre, que es en sí el producto de la cultura. “...si consideramos el producto de la actividad cultural: el hombre activo y libre, el hombre que puede prometer. Del mismo modo que la cultura es el elemento prehistórico del

${ }^{157}$ Ibíd., p. 195 
hombre, el producto de la cultura es el elemento post-histórico del hombre." ${ }^{158}$ Así, señalará que no hay que confundir al producto de cultura con su medio, no confundir el punto de vista prehistórico con el posthistórico. Asimismo, si bien él denomina a este capítulo como "el punto de vista posthistórico", no debemos pensar que se trata de otro período, como en el caso del prehistórico y el histórico. De este modo, comprendemos que este elemento del posthistórico como la finalidad de la cultura.

De esta manera, Deleuze distingue claramente a la cultura de su producto. Así, si bien la actividad genérica lo forma al hombre haciéndolo responsable de sus fuerzas reactivas y esta responsabilidad es medio de adiestramiento y selección, el producto de la cultura no es el hombre responsable, es el hombre autónomo, super-moral, irresponsable, que activa sus fuerzas reactivas. "El producto acabado de la actividad genérica no es de ningún modo el propio hombre responsable o el hombre moral, sino el hombre autónomo o super-moral, es decir el que verdaderamente activa sus fuerzas reactivas $y$ en quien todas las fuerzas reactivas son activadas." 159 Es el individuo soberano, legislador, que tiene poder sobre sí, sobre la ley, sobre el destino, es irresponsable. Así, el individuo autónomo ya no es responsable de sus fuerzas reactivas ante la justicia, es su señor, su soberano, su legislador. De esta manera, es claramente diferente este producto de la cultura de cualquiera de los dos tipos dados anteriormente, ya que se presenta como su propio legislador, soberano, etc.

De este modo, el medio de la cultura desaparece en su producto: la responsabilidad ante la ley, la ley como ley de justicia, la justicia como medio de la cultura, todo esto desaparece en el producto de la cultura. Por esto, se entiende que la moralidad de las costumbres produce un hombre separado de la moralidad de las costumbres. "La moralidad de las costumbres produce al hombre liberado de la moralidad de las costumbres..." ${ }^{160}$ De modo tal que la cultura como actividad genérica del hombre produce un objetivo final donde lo genérico es suprimido. Así, no podemos pensar que el hombre capaz de prometer, producto de la cultura como actividad genérica, sea la finalidad de la cultura. Esto también se puede afirmar si pensamos en

\footnotetext{
158 Ibíd., p. 192

${ }^{159}$ Ibíd., p. 193

${ }^{160}$ Ibídem.
} 
la responsabilidad de las fuerzas reactivas como un elemento más de la cultura como actividad genérica. “...el individuo autónomo ya no es responsable de sus fuerzas reactivas ante la justicia, es su señor, su soberano, su legislador, su autor y su actor." ${ }^{161}$

Por otro lado, nos queda saber si este elemento posthistórico del hombre, puede ser considerado un tipo activo, puesto que claramente está alejado de la reactividad. Comenzar esta búsqueda presupone comprender a este elemento posthistórico del hombre como un tipo de hombre. Sin embargo, dicha afirmación acarrea ciertos problemas. En principio, debemos decir que el pensador francés es bastante ambiguo al respecto, no dando una definición clara. Así, Deleuze se refiere a esta noción de dos maneras. Primero, lo denomina como "el elemento poshistórico del hombre", o sea, podríamos pensar que se refiere a algo diferente del hombre. ${ }^{162} \mathrm{Y}$ en otros pasajes se refiere como el hombre soberano, libre, irresponsable, etc.

Pero ¿Por qué el autor llamaría a un tipo hombre el elemento del hombre? Para aclarar un poco esto, recurrimos al final de la sección tercera, donde Deleuze sentencia que la cultura como actividad genérica tiene como último fin crear al filósofo y al artista. Asimismo, cuando se refiere a estos señala que son inventores de nuevas posibilidades de vida. "Para Nietzsche, nosotros los artistas $=$ nosotros los buscadores de conocimiento o de verdad $=$ nosotros los inventores de nuevas posibilidades de vida." ${ }^{163}$ Pero ¿A qué refiere con nuevas posibilidades de vida?: al superhombre: “...no el hombre sino el superhombre como nueva forma de vida. Si Nietzsche concede tanta importancia al arte, es precisamente porque el arte realiza todo este programa...." ${ }^{164}$ De este modo, se puede afirmar que los filósofos y los artistas son creadores de nuevas formas de vida, de superhombres.

Teniendo en cuenta esto, se puede observar cómo constantemente se diferencia al superhombre del hombre, ya que no lo considera como un tipo de hombre en sí. "No creamos que el superhombre de Nietzsche sea un afán de emulación: difiere en naturaleza con el hombre, con el yo. El superhombre se define por una nueva manera de sentir: otro sujeto que el hombre, otro tipo que el tipo

\footnotetext{
${ }^{161}$ Ibíd., p. 193

162 “...el producto de la cultura es el elemento post-histórico del hombre.” Ibíd., p. 192

${ }^{163}$ Ibíd., p. 145

${ }^{164}$ Ibídem.
} 
humano." ${ }^{165}$ Asimismo, muchas de las características del elemento posthistórico del hombre, se vinculan con las características dadas por el autor alemán hacia el superhombre. De esta manera, creemos comprender que el elemento posthistórico de la cultura no debe ser entendido como un tipo de subjetividad, sino como algo diferente de un sujeto. Asimismo, compartimos las tesis que lo vinculan con el concepto de "personajes conceptuales", que Deleuze desarrollará a posterior en ¿Qué es la filosofía? Sin embargo, no negamos posibles afirmaciones que sostengan al superhombre como un tipo de sujeto.

De este modo, entendemos que el fin último de la cultura como actividad genérica es la creación del elemento posthistórico del hombre, el superhombre. Asimismo, comprendemos que dicho elemento no debe ser considerado como un tipo de sujeto, sino como construcciones de los filósofos y los artistas, según señala Deleuze. Por otro lado, si comprendemos que se trata de "personajes conceptuales", debemos incluir a la ciencia y el arte dentro de esta posibilidad de creación de estos personajes.

\subsubsection{Relación entre los tipos de hombres y tipos de cultura.}

Deleuze afirma que el hombre es un ser esencialmente reactivo, pero que existe en él una actividad genérica irreparablemente deformada que termina en el hombre domesticado. Por otro lado, esa actividad debe ser tomada desde otro plano, sobre el que se produce, algo distinto del hombre. “...el hombre es esencialmente reactivo; no deja de haber una actividad genérica del hombre, pero necesariamente deformada, fracasando necesariamente en su finalidad, desembocando en el hombre domesticado; esta actividad debe ser considerada bajo otro plano, plano sobre el que produce, pero sobre el que produce algo distinto del hombre..."166 De nuevo, comprendemos que aquello que produce la actividad genérica es el elemento posthistórico (el superhombre), tal como lo señala Deleuze, del cual se destaca el carácter de "producto" diferente del hombre, creado en un plano diferente. De esta forma, deberíamos pensar que las subjetividades son esencialmente reactivas pero

\footnotetext{
${ }^{165}$ Ibíd., p. 230

${ }^{166}$ Ibíd., p. 197
} 
que a veces se puede observar cierta activada en los sujetos a través de la producción de superhombres.

Por otro lado, si comprendemos que el hombre capaz de prometer, el señor, el tipo activo, sólo es posible en una comunidad basada en una moralidad de las costumbres, o sea, en comunidades prehistóricas, comprendemos porqué Deleuze afirma que la cultura como actividad genérica ha desaparecido hace mucho y su producto no ha comenzado aún. "De la cultura hay que decir al mismo tiempo que ha desaparecido desde hace mucho tiempo y que todavía no ha empezado. La actividad genérica se pierde en la noche del pasado, como su producto en la noche del futuro." ${ }^{\prime 67}$

\subsection{Las instituciones y su relación con la cultura.}

En relación a este punto, es clara la relación que existe entre las instituciones y una cultura reactiva. Asimismo, Deleuze denuncia que toda la violencia de la cultura, la historia la presentará como propiedad legítima de los Estados o Iglesias, como una manifestación de su fuerza. Utilizan todos los procedimientos de adiestramiento pero invertidos, recordemos los dos elementos del adiestramiento (el primero, pertenecía a la cultura reactiva y se vinculaba con las instituciones). Así, las instituciones parecen tener un carácter siempre reactivo en Deleuze, de hecho destaca que la mismas no imaginan nada superior a ellas mismas, desviando las violencias de la cultura. "Ocurre que la Iglesia o el Estado toman por su cuenta esta violencia de la cultura para realizar sus propios fines. Ocurre que las fuerzas reactivas desvían esta violencia de la cultura, y la convierten en una fuerza reactiva, en un medio de entontecer todavía más, de rebajar el pensamiento." ${ }^{168}$ Asimismo, continuamente el pesador francés vincula a los elementos reactivos de la cultura con las instituciones. Recordemos el caso de ciertos filósofos, que son considerados por Deleuze como afines al Estado. Finalmente,

\footnotetext{
${ }^{167}$ Ibíd., p. 194

168 Ibíd., p. 155
} 
debemos destacar también un tipo de institución de justicia reactiva, en donde se confunde las leyes con el contenido. ${ }^{169}$

Por otro lado, en cuanto a la posibilidad de pensar instituciones activas, debemos decir que es posible cuando Deleuze señala una justicia activa, cuando analizábamos la cultura desde el punto de vista prehistórico. Así, si Deleuze piensa en este tipo de justicia es posible también que la misma esté acompañada por una institución propia. Así también podemos pensar en la idea de Estados primitivos propiamente activos.

En cuanto a la relación entre las instituciones y la construcción de subjetividades, el pensador francés no refiere a que dicha relación se dé de manera directa y unilateral. Así, no podríamos pensar que los Estados son la causa directa de la formación de determinados tipos de sujetos. Si bien señala que han contribuido en la formación de los mismos a través de sus violencias, entendemos que no se puede pensar a esta relación de manera directa. "Las principales actividades de las Iglesias y de los Estados constituyen más bien el largo martirologio de la propia cultura."170

Si bien, por un lado, el pensador expresa esta relación, no son únicamente los Estados los que contribuyen en la formación de sujetos, pensemos en cada uno de los elementos de la cultura. Asimismo, en el caso puntual de la filosofía el pensador francés destaca personajes puntuales como Kant, Hegel, Sócrates, etc., que contribuyen con el Estado. De manera tal que son los mismos sujetos quienes colaboran con la producción de instituciones. Así, la relación entre ambos no puede pensarse de manera causal. De igual modo, no se presenta al Estado únicamente como formador de sujetos, así hemos observado pasajes donde el mismo aparece al nivel de la moral u otros elementos de la cultura. Por ello, entendemos que Deleuze afirma que no es el Estado o demás instituciones las que producen un hombre domesticado, o

\footnotetext{
${ }^{169}$ En cuanto a la filosofía que el mismo autor francés defiende, el destaca la clara desvinculación que existe con respecto de las instituciones. "La filosofía no sirve ni al Estado ni a la Iglesia, que tienen otras preocupaciones. No sirve a ningún poder establecido" Ibíd., p. 149 Y más adelante dice: "Hacer hombres libres, es decir, hombres que no confundan los fines de la cultura con el provecho del Estado, la moral, o la religión." Ibíd., p. 150

${ }^{170}$ Ibíd., p. 154
} 
capaz de prometer, sino la cultura como fenómeno complejo que incluye a las instituciones quien lo hace.

\section{Conclusión.}

En relación a la cultura el pensador francés la define como adiestramiento y selección. Asimismo, ya traza directamente una relación entre esta y la formación de sujetos, puesto que este adiestramiento y selección se dirigen sobre el hombre. De esta forma, nosotros vamos a distinguir dos tipos de cultura en base al concepto deleuziano de fuerzas reactivas y activas. Así, indicaremos una cultura como actividad genérica y otra como triunfo de las fuerzas reactivas. De esta forma, vinculamos al hombre capaz de prometer como producto de la actividad genérica (tipo activo, responsable de sus fuerzas reactivas) y al hombre domesticado como producto de la reactividad (tipo reactivo, responsable/culpable de las fuerzas activas). Sin embargo, se destaca que el fin último de la actividad genérica no es el hombre capaz de prometer, sino el individuo soberano, algo diferente del hombre, el superhombre (el irresponsable). Así, el pensador francés remarca que no se debe confundir a la cultura, con su producto.

Por otro lado, si bien en principio el filósofo francés diferenciaba a las culturas en relación a la moral en, prehistórica e histórica, hemos señalado la presencia de otros elementos que la componen. De esta manera, señalábamos a la filosofía, la ciencia, la religión, la historia, y el lenguaje como partes de esta. Así, hemos observado como cada uno de estos elementos se vinculaba con la actividad y la reactividad. En un comienzo quedaba clara la relación con la reactividad, sin embargo la actividad presentaba ciertos problemas. Finalmente, los análisis con respecto al elemento posthistórico del hombre nos han servido de ayuda para esto. Así, hemos vinculado a la noción de superhombre, no con un tipo activo, sino con el concepto de personajes conceptuales desarrollados por Deleuze en ¿Qué es la filosofía? De modo tal que no se trataría de un tipo de subjetividades. Por otra parte, mediante esto hemos mostrado la vinculación entre el superhombre y la filosofía, la ciencia y el arte. 
De esta forma, Deleuze remarca el carácter formador de subjetividades que tiene la cultura, de manera tal que cada uno de los elementos señalados debe ser tomado también como un instrumento de la cultura para la producción de sujetos.

Por otra parte, analizamos las instituciones, las cuales en principio claramente se vinculan con la cultura de la historia, así Deleuze remarca este vínculo continua y directamente como pudimos observar en nuestros análisis. Sin embargo, también señalábamos la posible existencia de instituciones activas, en relación a lo que indicábamos sobre la justicia desde el punto de vista prehistórico y las religiones activas.

Finalmente, en relación a las instituciones y las subjetividades pudimos observar que la relación entre ambas no se da de manera causal. Así, hemos señalado que tanto personajes puntuales como Kant, Sócrates, Hegel, podrían contribuir con la formación de instituciones y perpetuación de estas. Por otro lado, también las mismas instituciones tienen un carácter formador. Sin embargo, la cultura, como fenómeno complejo, es señalada por Deleuze como formadora de subjetividades. Por ello, es la cultura un concepto clave para comprender el complejo conjunto de fenómenos que envuelve la formación de sujetos. 